\title{
Increased Yield of Biotransformation of Androsta-1, 4-Dien-3, 17-Dione from B-Sitosterol by Using Sulfobutyl Ether-B-Cyclodextrin Complexation Technique
}

\author{
Jingwen $\mathrm{WANG}^{1, \mathrm{a}}$, Shimin GUAN ${ }^{1, \mathrm{~b}}$, Baoguo $\mathrm{CAI}^{1, \mathrm{c}}$, Shuo $\mathrm{ZHANG}^{1, \mathrm{~d}}$, Shulin $\mathrm{YANG}^{1, \mathrm{e}}$, \\ Yue ZHOU ${ }^{1, f}$, Shaofeng RONG ${ }^{* 1, g}$ and Qianqian $\mathrm{LI}^{* 1, \mathrm{~h}}$ \\ ${ }^{1}$ School of Perfume and Aroma Technology, Shanghai Institute of Technology,100 Haiquan Road, \\ Fengxian District, Shanghai 201418,P. R. China \\ awenjingwang1026@163.com, ${ }^{\mathrm{a}}$ guanshimin0000@163.com, ${ }^{\mathrm{c}}$ baoguocai@126.com, \\ dzhangshuo0430@163.com, ${ }^{\mathrm{d}}$ luoyangyslin@163.com, ${ }^{\mathrm{f}} \mathrm{zhouyue1109@126.com,}$ \\ grongshaofeng@163.com, hlqq3486@163.com
}

\begin{abstract}
Substrate solubility in steroid biotransformation is critical for enhancing the biotransformation of hydrophobic compounds. In this study, the sulfobutyl ether- $\beta$-cyclodextrin (SBE- $\beta$-CD) complexation technique was used for the biotransformation of $\beta$-sitosterol to androsta-1, 4-diene-3, 17-dione with Mycobacterium ATCC25795. The production yield was increased by $26.72 \%$, and the biotransformation course was shortened by $24 \mathrm{~h}$ using $\beta$-sitosterol/SBE- $\beta$-CD inclusion complexes as substrates $(1.0$ $\mathrm{g} / \mathrm{L}$ ). Fourier transform infrared spectroscopy and differential scanning calorimetry indicated that an inclusion complex was formed between SBE- $\beta$-CD and $\beta$-sitosterol. The complex significantly increased the solubility of $\beta$-sitosterol and improved the biotransformation efficiency of the substrate.
\end{abstract}

Keywords: $\beta$-sitosterol; biotransformation; Mycobacterium; androsta-1, 4-dien-3, 17-dione

\section{Introduction}

Androsta-1, 4-diene-3, 17-dione (ADD) and its derivatives are important intermediates for numerous steroid drugs [1]. ADD is mainly obtained from steroids, via biotransformation with microorganisms, such as Mycobacterium, Gordonia neofelifaecis, and Bacillus sphaericus. These microorganisms can transform steroids into ADD through side-chain cleavage of the substrate molecules [2-4]. However, the low solubility of steroids in aqueous environment limits their potential application.

To solve this problem, researchers have conducted various methods to improve substrate solubility. The use of organic-aqueous system increases the productivity of biotransformation because of the dissolution of steroid substrate [5]. Cloud-point systems

${ }^{*}$ Corresponding author: Shaofeng Rong and Qianqian Li 
were developed for their effect on upstream processes and potential use in product separation [6]. However, organic solvents and surfactants must be non-toxic for microorganisms. The amount of added reagent is usually limited, which is a difficult task to achieve.

Cyclodextrins (CDs) is a cone-shaped ring, which built up from $\alpha$-(1, 4)-glucopyranose units. CDs, especially modified CDs, are widely applied in biotransformation of steroids [7, 8]. Given the large intermolecular hydrophobic torus cone-like cavity and highly hydrophilic external surface of CDs, they are easy to form inclusion complexes with various hydrophobic compounds. In addition, CDs have no side effects on microorganisms. They can also increase the permeability of cell membrane, which makes them more conducive for transformation [9].

In this work, we investigated the biotransformation of $\beta$-sitosterol to ADD with Mycobacterium ATCC25795 (Fig. 1). Sulfobutyl ether- $\beta$-cyclodextrin (SBE- $\beta$-CD) complex was applied to increase the solubility of substrate. The method increased the conversion efficiency of $\beta$-sitosterol. This finding is significant for steroid biotransformation and could be employed for biotransformation of other steroid precursors that have poor solubility.

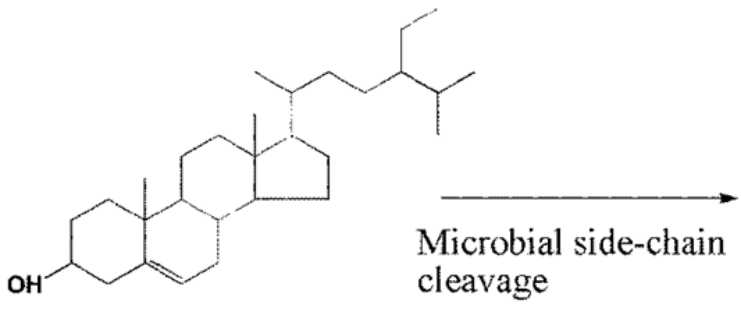

$\beta$-sitosterol

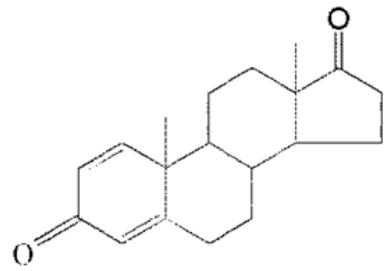

ADD

Fig. $1 \beta$-Sitosterol side-chain cleavage reaction. ADD, androsta-1, 4-diene-3, 17-dione.

\section{Materials and Methods}

\subsection{Chemicals}

ADD was purchased from Sigma (USA). $\beta$-Sitosterol and SBE- $\beta$-CD were obtained from SCIPHAR (China) and Zhiyuan Bio-Technology (China), respectively. Reagents and solvents were of analytical grade and obtained from commercial sources.

\subsection{Strain and culture medium}

The strain Mycobacterium ATCC25795 was obtained from American Type Culture Collection (ATCC). This strain was stored and maintained in $30 \%(\mathrm{v} / \mathrm{v})$ glycerol stock solutions at $-80{ }^{\circ} \mathrm{C}$.

The seed medium of Mycobacterium ATCC25795 consisted of the following: $\mathrm{KH}_{2} \mathrm{PO}_{4}$, $1.5 \mathrm{~g} / \mathrm{l}$; yeast extract, $6.0 \mathrm{~g} / \mathrm{l} ; \mathrm{MgSO}_{4} \cdot 7 \mathrm{H}_{2} \mathrm{O}, 2.5 \mathrm{~g} / \mathrm{l}$; and glucose, $5.0 \mathrm{~g} / 1$ (adjusted to $\mathrm{pH}$ 7.0).

The fermentation medium included the following components: glucose, $8.0 \mathrm{~g} / 1 ; \mathrm{K}_{2} \mathrm{HPO}_{4}$, $1.0 \mathrm{~g} / \mathrm{l} ; \mathrm{KH}_{2} \mathrm{PO}_{4}, 1.0 \mathrm{~g} / \mathrm{l}$; ferric ammonium citrate, $0.05 \mathrm{~g} / \mathrm{l} ; \mathrm{MgSO}_{4} \cdot 7 \mathrm{H}_{2} \mathrm{O}, 2.5 \mathrm{~g} / \mathrm{l}$; and peptone, $5.0 \mathrm{~g} / 1$ (adjusted to $\mathrm{pH} 7.0$ ). 


\subsection{Transformation of $\beta$-sitosterol}

$\beta$-Sitosterol transformation was performed in 500ml Erlenmeyer flasks containing $95 \mathrm{ml}$ of fermentation medium. The fermentation medium was sterilized and inoculated with $5 \mathrm{ml}$ of exponentially growing seed solution of Mycobacterium ATCC25795. Subsequently, fine powder of $\beta$-sitosterol or $\beta$-sitosterol/SBE- $\beta$-CD inclusion complexes were added into the medium and incubated at $30{ }^{\circ} \mathrm{C}$ on a rotary shaker at $200 \mathrm{rpm}$.

\subsection{Product extraction and analytical methods}

After completion of the incubation, the culture broth was extracted three times by using an equal volume of ethyl acetate $(\mathrm{v} / \mathrm{v})$. The organic phase was collected by centrifugation at $1,2000 \mathrm{r} / \mathrm{min}$ for $15 \mathrm{~min}$, filtered. The extract was then evaporated under reduced pressure.

Thin layer chromatography: Layers of silica gel G from Qingdao (China) were prepared on glass plates and activated at $110^{\circ} \mathrm{C}$ for $1 \mathrm{~h}$ before use. Chromatography was performed with ethyl acetate/petroleum ether (3:7), and $\beta$-sitosterol was visualized by spraying the plates with $25 \%$ of sulfuric acid and heating in an oven at $120{ }^{\circ} \mathrm{C}$ for 30 min until colors developed.

High-performance liquid chromatography: ADD was analyzed using reverse-phase HPLC (Agilent Technologies, USA) with XDB-C18 column $(250 \mathrm{~mm} \times 4.6 \mathrm{~mm} ; 5 \mu \mathrm{m})$. The analysis was conducted with the following conditions: acetonitrile: water (mobile phase), 80:20 (v/v); UV detection, $254 \mathrm{~nm}$; column temperature, $25{ }^{\circ} \mathrm{C}$; and flow rate, 1 $\mathrm{ml} / \mathrm{min}$. ADD (98-99\% purity) was used as standard.

Molar yield of metabolite conversion was estimated as follows:

Molar yield $(\%)=\frac{\text { Weight of product } / \mathrm{MW} \text { of product }}{\text { Weight of substrate } / \mathrm{MW} \text { of substrate }} \times 100$,

where MW is the molecular weight.

\subsection{Preparation of the inclusion complexes of $\beta$-sitosterol with SBE- $\beta-C D$}

The inclusion complexes between $\beta$-sitosterol and SBE- $\beta$-CD were prepared by freeze-drying with a ZD-F20 Labconco (China). SBE- $\beta$-CD with different molar ratios was dispersed in aqueous solution. $\beta$-Sitosterol was added in the solution under stirring. Afterward, $\beta$-sitosterol and SBE- $\beta$-CD were mixed at room temperature for $48 \mathrm{~h}$ until complex was achieved at an equilibrium state. The suspension was frozen at $-80{ }^{\circ} \mathrm{C}$ and lyophilized in a freeze dryer.

\subsection{Fourier transform infrared spectroscopy (FTIR)}

FTIR of $\beta$-sitosterol, SBE- $\beta-C D$, and inclusion complexes were performed with a Nicolet iz10 FTIR spectrophotometer (Thermo Scientific, USA) in the range of 4000-400 $\mathrm{cm}^{-1}$. The samples were mixed with potassium bromide pellets to form tablet samples.

\subsection{Differential scanning calorimetry (DSC)}

DSC analysis of $\beta$-sitosterol, SBE- $\beta-\mathrm{CD}$, and inclusion complexes were conducted using a Q2000 thermal analyzer from TA Instruments (USA) from $40{ }^{\circ} \mathrm{C}$ to $170{ }^{\circ} \mathrm{C}$ at a 
heating rate of $10{ }^{\circ} \mathrm{C} / \mathrm{min}$ with nitrogen as the carrier gas. Approximately $5.0 \mathrm{mg}$ of samples were heated in sealed aluminum pans.

\section{Results and Discussion}

\subsection{Effect of molar ratio (SBE- $\beta$-CD: $\beta$-sitosterol) on $\beta$-sitosterol biotransformation efficiency}

For the biotransformation of $\beta$-sitosterol to $\mathrm{ADD}$, side-chain cleavage reaction was successfully performed using Mycobacterium ATCC25795.

CDs are widely applied in the biotransformation of steroids. Natural CDs include $\alpha-, \beta-$, $\gamma-$, and $\delta-C D$, with six, seven, eight and nine glucose units, respectively [10]. Several modified hydrophilic CD derivatives, such as hydroxypropyl- $\beta$-cyclodextrin, carboxymethyl- $\beta$-cyclodextrin, methyl- $\beta$-cyclodextrin, and SBE- $\beta-C D$, have been employed to increase aqueous solubility. Among the modified CDs, we studied the complexation of $\beta$-sitosterol with SBE- $\beta$-CD.

Results showed that the product concentration and molar yield were increased with increasing SBE- $\beta$-CD concentrations (Fig. 2). However, opposite results were found when the SBE- $\beta$-CD to $\beta$-sitosterol ratio was more than $2: 1$. This result suggests that a high SBE- $\beta$-CD concentration may prevent or delay the side-chain cleavage of $\beta$-sitosterol. At the optimum molar ratio of $2: 1$, the product concentration and molar yield were $0.682 \mathrm{~g} / \mathrm{L}$ and $98.87 \%$, respectively. However, the control samples without SBE- $\beta-C D$ achieved only $0.493 \mathrm{~g} / \mathrm{L}$ and $71.89 \%$.

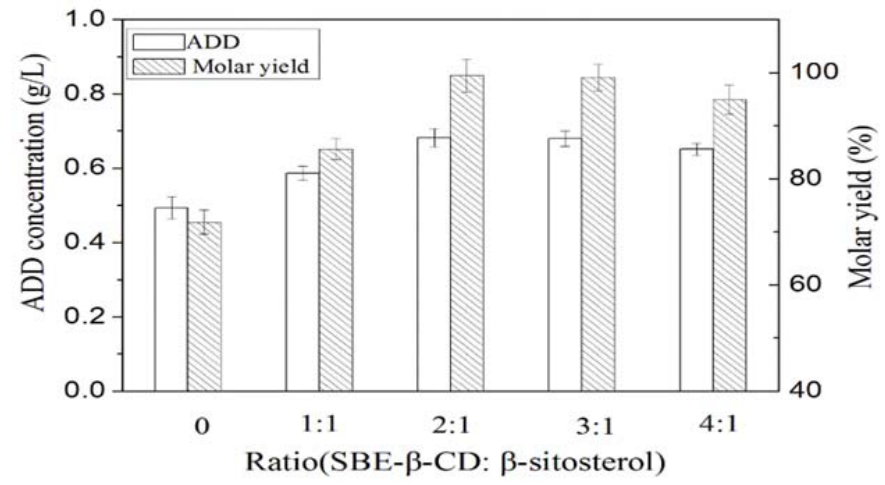

Fig. 2 Effect of molar ratio of SBE- $\beta$-CD to $\beta$-sitosterol on $\beta$-sitosterol biotransformation efficiency.

The results are the average of three replicates.

\subsection{Time course of biotransformation}

The results of production concentration and the change of substrate were monitored during biotransformation. When $\beta$-sitosterol was employed as substrate, the product concentration of ADD was $0.496 \mathrm{~g} / \mathrm{L}$ and the molar yield was $72.03 \%$ (Fig. 3A). The use of $\beta$-sitosterol/SBE- $\beta$-CD as substrate resulted in production concentration of $0.680 \mathrm{~g} / \mathrm{L}$ and molar yield of $98.75 \%$ (Fig. 3B), which increased by $26.72 \%$ compared with $\beta$-sitosterol. Meanwhile, the biotransformation was shortened by $24 \mathrm{~h}$. 
The low solubility of $\beta$-sitosterol was a bottleneck for biotransformation. Complexation with $\mathrm{CD}$ enhanced the biotransformation efficiency in an aqueous fermentation system because of the special structure of CD [10]. Moreover, CD caused the changes of the cell membrane permeability, which was favorable for biotransformation [9].
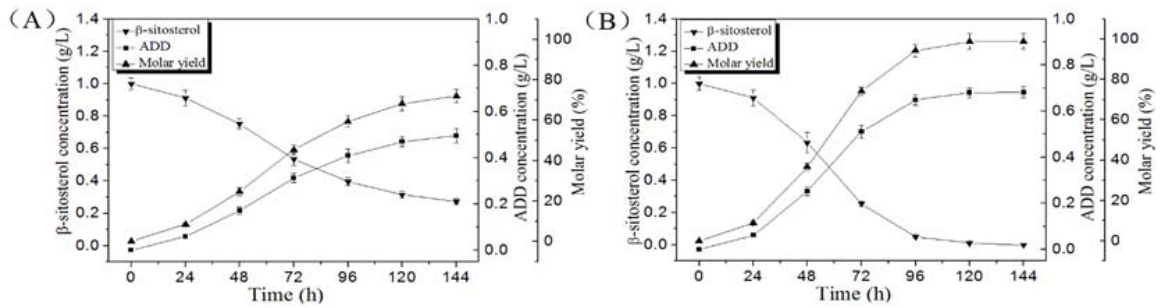

Fig. 3 Time course of product concentration by using $\beta$-sitosterol (A) or $\beta$-sitosterol/SBE- $\beta$-CD inclusion complexes (B) as substrate (1.0g/L), the molar ratio of SBE- $\beta$-CD to $\beta$-sitosterol was $2: 1$.

The results are the average of three replicates.

\subsection{Characterization of $\beta$-sitosterol/SBE- $\beta$-CD inclusion complexes FTIR spectra analysis}

Fig. 4A displays the FTIR spectra of $\beta$-sitosterol/SBE- $\beta$-CD inclusion complexes, SBE- $\beta$-CD, and $\beta$-sitosterol. The IR spectrum of $\beta$-sitosterol (Fig. 4A, c) exhibited a broad stretching peak at $3348.21 \mathrm{~cm}^{-1},-\mathrm{OH}$ stretching vibration, $\mathrm{C}-\mathrm{H}$ stretching band at 2933.95 $\mathrm{cm}^{-1}$, and $\mathrm{C}-\mathrm{H}$ asymmetrical stretching band at a $2865.47 \mathrm{~cm}^{-1}$. The absorption peak around $1665.17 \mathrm{~cm}^{-1}$ is a characteristic peak of $\mathrm{C}=\mathrm{C}$. The absorption peaks around 1457.69 and $1379.83 \mathrm{~cm}^{-1}$ were the $\mathrm{C}-\mathrm{H}$ bending vibration.

The IR spectrum of SBE- $\beta$-CD (Fig. 4A, b) exhibited a broad and strong absorption band at 3418.35 and $3007.57 \mathrm{~cm}^{-1}$. This result is attributed to the vibration absorption of free and association -OH groups. The absorption peaks at 2929.46 and at $1045.27 \mathrm{~cm}^{-1}$ were the $-\mathrm{CH}$ vibration absorption and $\mathrm{C}=\mathrm{O}$ vibration, respectively. In addition, the absorption peaks around $1128.21 \mathrm{~cm}^{-1}$ were attributed to the stretching vibration of the $\mathrm{C}-$ $\mathrm{O}$ groups. The peaks at $607.49 \mathrm{~cm}^{-1}$, which correspond to the stretching vibration of glucose ring, were the characteristic peaks of SBE- $\beta-C D$.

The IR spectrum of $\beta$-sitosterol/SBE- $\beta$-CD inclusion complexes (Fig. 4A, a) showed that the vibration absorptions of free and association $-\mathrm{OH}$ groups, $\mathrm{C}-\mathrm{O}$ stretching vibration, and $\mathrm{C}=\mathrm{O}$ stretching vibration were $3418.21,3007.25,1127.38$, and $1044.31 \mathrm{~cm}^{-1}$, respectively. The results indicate the unbroken structure of SBE- $\beta-C D$. The characteristic bands of $\beta$-sitosterol disappeared in the spectrum of the inclusion complex of $\beta$-sitosterol/SBE- $\beta$-CD. Studies showed that SBE- $\beta-C D$ has inclusion effect for hydrophobic substrates [11]. These results confirm the formation of inclusion complexes between $\beta$-sitosterol and SBE- $\beta$-CD.

\subsection{DSC analysis}

DSC analyses of $\beta$-sitosterol, SBE- $\beta$-CD, and $\beta$-sitosterol/SBE- $\beta$-CD inclusion complexes are shown in Fig. 4B. The DSC thermogram of $\beta$-sitosterol (Fig. 4B, c) showed a sharp endothermic peak at $139.1{ }^{\circ} \mathrm{C}$, which was consistent with its fusion peak. According to previous studies, the melting point of $\beta$-sitosterol is $140.1{ }^{\circ} \mathrm{C}$ [12]. The first 
peak of $\beta$-sitosterol thermogram at $101.9^{\circ} \mathrm{C}$ indicates the loss of impurities in the substrate. The DSC curve of SBE- $\beta$-CD (Fig. 4B, b) exhibited a wide fusion peak at $113.4{ }^{\circ} \mathrm{C}$. However, the sharp endothermic peak of $\beta$-sitosterol disappeared in the $\beta$-sitosterol/SBE- $\beta$-CD inclusion complexes (Fig. 4B, a). The results revealed the formation of $\beta$-sitosterol/SBE- $\beta$-CD inclusion complexes.
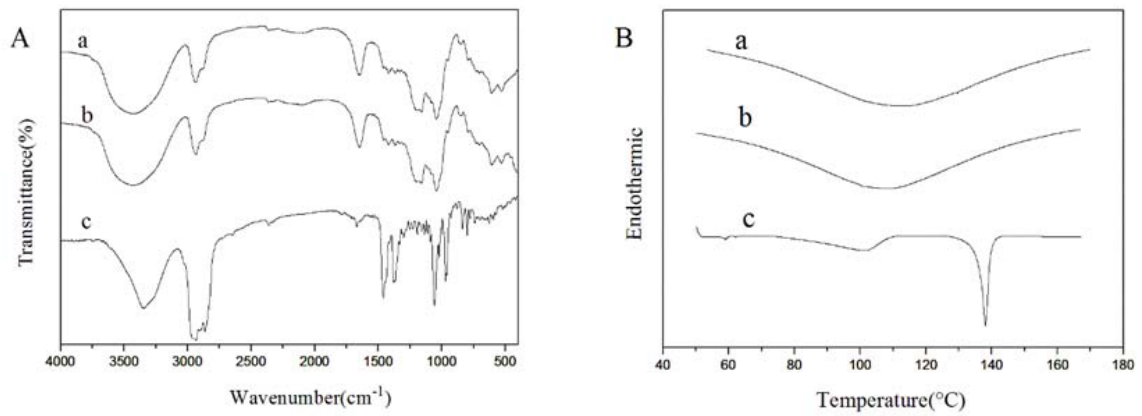

Fig. 4 FTIR spectra (A) and DSC thermograms (B) of $\beta$-sitosterol/SBE- $\beta$-CD inclusion complexes (a), SBE- $\beta$-CD (b), and $\beta$-sitosterol (c).

\section{Acknowledgments}

This work was supported by grants from the Science and Technology Commission of Shanghai Municipality (Grant No. 14120503400), the National Natural Science Foundation of China (Grant No. 31301475), the Science and Technology Commission of Shanghai Municipality (Grant No. 11DZ1921405), and the Economy and Informatization Commission of Shanghai Municipality (Grant No. CXY-2013-78).

\section{References}

1. A. Malaviya and J. Gomes, Androstenedione production by biotransformation of phytosterols, Bioresour. Technol. 99 (2008) 6725-6737.

2. O.V. Egorova, V.M. Nikolayeva, G.V. Sukhodolskaya, M.V. Donova, Transformation of C19-steroids and testosterone production by sterol-transforming strains of Mycobacterium spp, J. Mol. Catal. B: Enzym. 57(2009) 198-203.

3. Y. Liu, G. Chen, F. Ge, W. Li, L. Zeng, W. Cao, Efficient biotransformation of cholesterol to androsta-1, 4-diene-3, 17-dione by a newly isolated actinomycete Gordonia neofelifaecis, World J. Microbiol. Biotechnol. 27 (2011) 759-765.

4. S.K. Venu Gopal, S. Naik, P. Somal, P. Sharma, A. Arjuna, R. Ul Hassan, R.K. Khajuria, G.N. Qazi, Production of 17-keto androstene steroids by the side chain cleavage of progesterone with Bacillus sphaericus, Biocatal. Biotransform. 26 (2008) 272-279.

5. A. Cruz, P. Fernandes, J.M.S. Cabral, H.M. Pinheiro, Effect of phase composition on the whole-cell bioconversion of $\beta$-sitosterol in biphasic media, J. Mol. Catal. B: Enzym. 20 (2002) 371-375.

6. Z. Wang, J. $\mathrm{Xu}$ and $\mathrm{D}$. Chen, Whole cell microbial transformation in cloud point system, J. Ind. Microbiol. Biotechnol. 35 (2008) 645-656.

7. S.S. Mohamed, A.H. El-refai, A.M. Hashem, H.A. Ali, Approaches to improve the solubility and availability of progesterone biotransformation by Mucor racemosus. 
Biocatal. Biotransform. 32 (2014) 141-150.

8. Y. Shen, M. Wang, H. Li, Y. Wang, J. Luo, Influence of hydroxypropyl- $\beta$-cyclodextrin on phytosterol biotransformation by different strains of Mycobacterium neoaurum. J. Ind. Microbiol. Biotechnol. 39 (2012) 1253-1259.

9. Y. Wu, H. Li, Z. Lu, H. Li, Z. Rao, Y. Geng, J. Shi, Z. Xu, Enhancement of steroid hydroxylation yield from dehydroepiandrosterone by cyclodextrin complexation technique, Steroids. 84 (2014) 70-77.

10. S. Kwon, W. Lee, H.J. Shin, S. Yoon, Y. Kim, Y.J. Kim, K. Lee, S. Lee, Characterization of cyclodextrin complexes of camostat mesylate by ESI mass spectrometry and NMR spectroscopy, J. Mol. Struct. 938(2009) 192-197.

11. X. Zhao, X. Li, J. Wang, K. Zhao, L. Zhang, Inclusion effect of sulfobutyl ether- $\beta$-cyclodextrin on lansoprazole, Zhongguo Yiyao Gongye Zazhi. 46 (2015)167-171.

12. O. Sha, Q. Shao, B. Huang, W. Xu, Characterization of succinate in the reaction process of phytosterol with succinic anhydride, Zhongguo Youzhi. 29(2004) 34-37. 